\title{
Correção do mosto da uva Isabel com diferentes produtos na Serra Gaúcha
}

\author{
Must correction of the Isabel grape with different products in the \\ Serra Gaúcha - RS, Brazil
}

Luiz Antenor Rizzon ${ }^{1}$ Alberto Miele ${ }^{2}$

\section{RESUMO}

A uva Isabel da Serra Gaúcha geralmente não alcança teor de açúcar suficiente para produzir vinho equilibrado $e$, em determinados casos, para atingir $10 \% \mathrm{v} / \mathrm{v}$ de álcool, concentração mínima para vinho de mesa estabelecida pela legislação brasileira. O objetivo do presente trabalho foi avaliar o efeito de diferentes produtos utilizados para correção do mosto na composição química do vinho Isabel. O experimento constou de seis tratamentos: testemunha (sem correção), sacarose, açúcar mascavo, mosto concentrado, álcool vínico e glicose de milho. Os vinhos foram elaborados em microvinificações, com seis repetições. As amostras foram avaliadas através das análises clássicas, efetuadas por métodos físico-químicos, e dos elementos minerais por absorção atômica. A sacarose foi o produto mais adequado para a correção do mosto, pois não incorporou componentes estranhos, não alterou a relação álcool em peso/ extrato seco reduzido e apresentou elevado rendimento alcoólico. O álcool vínico pode ser utilizado desde que seja um produto genuíno de procedência garantida, preferencialmente obtido de vinho branco.

Palavras-chave: Vitis labrusca, chaptalização, teor alcoólico.

\section{ABSTRACT}

The cv. Isabel grown in the Serra Gaúcha region in general does not produce a balanced wine, because it sometimes does not reach, the minimum stablished by Brazilian legislation $10 \% \mathrm{v} / \mathrm{v}$ of alcohol. The aim of this work was to evaluate the effects of different products used in the must sugar correction on the chemical composition of the Isabel wine. The experiment had six treatments - control (without correction) and correction with saccharose, brown sugar, concentrated must, wine alcohol and mayz glucose; there were six replications. The wine was elaborated by microvinification. The samples were evaluated through classical analysis made by physico-chemical methods and the mineral elements determined by atomic absorption.
Results showed that saccharose was the most adequate product for chaptalisation because it did not introduce foreign substances, and neither changed the alcohol in weight/reduced dry extract ratio and showed to be a high alcohol producer. The wine alcohol may be used when it is from a guarantee origin, especially if it is made from white wine.

Key words: Vitis labrusca, chaptalisation, alcohol content.

\section{INTRODUÇÃO}

Chaptalização é a prática que consiste na correção da deficiência de açúcar da uva com sacarose, sendo difundida por Jean Antoine Chaptal (17561832). Além de favorecer o equilíbrio do vinho através da elevação do grau alcoólico, a chaptalização também contribui na extração dos compostos fenólicos e aromáticos durante a maceração da uva (CHAPTAL, 1981).

A uva Isabel produzida na Serra Gaúcha geralmente não alcança teor de açúcar suficiente para produzir um vinho equilibrado e, em determinados casos, para atingir 10\% v/v de álcool, concentração mínima estabelecida pela legislação brasileira (BRASIL, 1974). Isso determina a prática da chaptalização na região.

A correção do mosto, quando efetuada, não deve incorporar substâncias estranhas ao vinho. A sacarose transforma-se em etanol e produtos secundários da fermentação, o mesmo que ocorre com a glicose e a frutose, ambas presentes no mosto.

${ }^{1}$ Engenheiro Agrônomo, Doutor, Empresa Brasileira de Pesquisa Agropecuária (Embrapa) Uva e Vinho, Rua Livramento, 515 CP 130, 95700-000, Bento Gonçalves, RS. E-mail: rizzon@cnpuv.embrapa.br. Autor para correspondência.

${ }^{2}$ Engenheiro Agrônomo, Doutor, Embrapa Uva e Vinho. E-mail: miele@cnpuv.embrapa.br 
O excesso de precipitação pluviométrica no período de maturação da uva é o principal fator responsável pelo baixo teor de açúcar dos mostos da Serra Gaúcha (ROSEK, 1965). Em alguns casos, a correção do mosto com desacidificantes, também é recomendável para diminuir a acidez do vinho Isabel, tornando-o mais equilibrado e apreciado pelos consumidores.

O teor de açúcar do mosto pode ser corrigido através da adição de sacarose, mosto concentrado ou mosto concentrado retificado, enquanto que a correção do grau alcoólico do vinho é efetuada geralmente com álcool vínico. A glicose de milho e o açúcar mascavo não são permitidos para a correção do mosto, mas foram utilizados na pesquisa para fornecer subsídios aos órgãos responsáveis pelo controle da produção e comercialização dos vinhos, para detectar vinhos elaborados com a adição desses produtos.

A sacarose é o açúcar recomendado para efetuar a chaptalização (RIBÉREAU-GAYON et al., 1998). Na Itália não é permitida a adição de sacarose, tanto na forma sólida quanto em xarope (AMATI et al., 1980). Naquele país, a correção pode ser feita com mosto concentrado e mosto concentrado retificado. No entanto, estes autores admitem ser aceitável, sob o ponto de vista técnico, a utilização de sacarose nos vinhos de mesa, enquanto propõem a utilização de açúcar de uva (mosto concentrado retificado) nos vinhos de Denominação de Origem Controlada (DOC). A chaptalização utilizada de forma controlada contribui para melhorar a qualidade do vinho, pois não altera o equilíbrio entre os constituintes fixos e voláteis, mas quando aplicada de modo excessivo descaracteriza-o e aumenta seu volume.

O limite máximo da relação álcool em peso/ extrato seco reduzido estabelecido pela legislação brasileira (BRASIL, 1974) tem a finalidade de controlar os excessos de correção do mosto com sacarose. Atualmente, o controle analítico da chaptalização dos vinhos brasileiros é feito através da análise da relação isotópica ${ }^{12} \mathrm{C} /{ }^{13} \mathrm{C}$ (BRASIL, 2000), sendo o máximo permitido de 3\% v/v de álcool. O objetivo do trabalho foi comparar o efeito de diferentes produtos (sacarose, açúcar mascavo, mosto concentrado, álcool vínico e glicose de milho) utilizados para a correção do mosto, na composição química do vinho Isabel.

\section{MATERIAL E MÉTODOS}

Utilizou-se uva Isabel proveniente dos municípios de Flores da Cunha e Farroupilha, RS.
Inicialmente, foram formados lotes homogêneos de $18 \mathrm{~kg}$. A uva foi separada da ráquis, esmagada e colocada em recipientes de vidro de $20 \mathrm{~L}$, ocasião em que recebeu uma dose de $40 \mathrm{mg} \mathrm{L}^{-1}$ de dióxido de enxofre e $0,2 \mathrm{~g} \mathrm{~L}^{-1}$ de levedura seca ativa (Saccharomyces cerevisiae). Em cada recipiente, foi utilizada uma válvula de Müller de vidro para evitar a entrada de ar e permitir a saída do dióxido de carbono formado na fermentação alcoólica. Esses recipientes constituíram as unidades experimentais.

Os tratamentos constaram em corrigir o mosto com os seguintes produtos: testemunha (sem correção), sacarose com mais de $99 \%$ de pureza, açúcar mascavo comercial, mosto concentrado com $68^{\circ} \mathrm{Brix}$, álcool vínico com $87 \%$ v/v e glicose de milho comercial. Adicionou-se a quantidade necessária de cada produto para aumentar $1,5 \% \mathrm{v} / \mathrm{v}$ de álcool. Os produtos foram adicionados ao mosto em duas épocas distintas, sendo uma no início da fermentação alcoólica, isto é, dois dias após o esmagamento da uva e a outra por ocasião da descuba, que ocorreu cinco dias após o esmagamento. Durante o período de maceração foram efetuadas duas remontagens diárias e os recipientes permaneceram numa sala climatizada a $25^{\circ} \mathrm{C}$. Os produtos utilizados na correção foram inicialmente diluídos com um pouco de mosto e posteriormente adicionados no recipiente de fermentação. Uma vez concluída a fermentação alcoólica, os vinhos foram estabilizados, filtrados - ocasião em que receberam mais uma dose de $50 \mathrm{mg} \mathrm{L}^{-1}$ de dióxido de enxofre - e engarrafados.

Os vinhos foram analisados quanto ao álcool, densidade, acidez total e volátil, $\mathrm{pH}$, extrato seco, açúcares redutores, extrato seco reduzido, cinzas e alcalinidade das cinzas, conforme metodologia descrita por GIANNESSI \& MATTA (1987).

Os polifenóis totais, antocianinas e taninos foram determinados segundo RIBÉREAU-GAYON \& STONESTREET (1965 e 1966). Os índices de cor I 420 e I 520, a intensidade de cor e a coloração foram obtidas através da leitura efetuada diretamente no espectrofotômetro com uma cubeta de $1 \mathrm{~mm}$ de percurso ótico.

Os cátions ( $\mathrm{Ca}, \mathrm{Mg}, \mathrm{Mn}, \mathrm{Fe}, \mathrm{Cu}$ e $\mathrm{Zn}$ ) foram determinados por espectrofotometria de absorção atômica, enquanto que o K, Na e Li por emissão de chama (PERKIN-ELMER, 1976). O teor de P foi determinado por colorimetria, utilizando molibdato de amônio (TEDESCO et al., 1995).

O delineamento experimental utilizado foi o completamente casualizado, com seis tratamentos e seis repetições. Os resultados obtidos foram 
submetidos ao teste de Tukey para comparação das médias, a $1 \%$ de probabilidade de erro.

\section{RESULTADOS E DISCUSSÃO}

O resultado analítico do vinho Isabel corrigido com diferentes produtos está indicado na tabela 1. Em relação ao grau alcoólico, que é o objetivo principal da chaptalização, observou-se que o álcool vínico apresentou o valor mais elevado, diferindo significativamente dos demais tratamentos, exceção à sacarose. O álcool vínico é um produto enológico permitido para efetuar a correção do mosto. A vantagem de utilizá-lo no mosto, na vinificação em tinto, é favorecer a extração de componentes da película proporcionando maior estrutura ao vinho. No entanto, quando utilizado, recomenda-se sempre empregar um produto genuíno, com garantia de procedência, obtido preferencialmente de vinho branco e com a graduação alcoólica mais elevada possível. O rendimento alcoólico do vinho corrigido com sacarose não diferiu daquele corrigido com açúcar mascavo. Os vinhos corrigidos com mosto concentrado e com glicose de milho mostraram rendimento alcoólico inferior, devido à constituição química desses produtos. No caso da glicose de milho, além de apresentar quantidade considerável de açúcar não fermentescível, possui componentes que aumentam o extrato seco reduzido dos vinhos. A glicose de milho não é permitida para chaptalização dos vinhos brasileiros devido à presença de quantidade elevada de açúcar não fermentescível. Em nenhum caso, constatou-se rendimento integral do álcool, provavelmente em conseqüência de perdas na transformação e sensibilidade analítica.

Quanto à variação da densidade do vinho, ela ocorre em conseqüência principalmente do grau alcoólico e, no caso específico do vinho corrigido com glicose de milho, devido ao teor de substâncias não fermentescíveis.

O mosto concentrado aumentou o teor de acidez total. Isso acontece normalmente, uma vez que, além do açúcar, são incorporados especialmente os ácidos orgânicos málico e tartárico, que compõem o mosto concentrado. Pequenos decréscimos observados na acidez total e aumentos no valor do pH de alguns vinhos corrigidos, deveram-se ao aumento do grau alcoólico e conseqüente insolubilização de maior quantidade de bitartarato de potássio. Nesse sentido, a utilização de mosto concentrado na chaptalização do vinho Isabel se constitui num problema, devido ao teor natural de

Tabela 1 - Influência de produtos utilizados na correção do mosto na composição química do vinho Isabel.

\begin{tabular}{|c|c|c|c|c|c|c|c|c|}
\hline \multirow[b]{2}{*}{ Variáveis } & \multicolumn{8}{|c|}{ Produtos utilizados* } \\
\hline & Testemunha & Sacarose & $\begin{array}{c}\text { Mosto } \\
\text { concentrado }\end{array}$ & $\begin{array}{l}\text { Açúcar } \\
\text { mascavo }\end{array}$ & $\begin{array}{l}\text { Glicose } \\
\text { de milho }\end{array}$ & $\begin{array}{l}\text { Álcool } \\
\text { vínico }\end{array}$ & $\begin{array}{l}\text { Média } \\
\text { geral }\end{array}$ & $\begin{array}{l}\mathrm{CV} \\
(\%)\end{array}$ \\
\hline Densidade a $20^{\circ} \mathrm{C}$ & $0,9970 \mathrm{~b}$ & $0,9954 \mathrm{~d}$ & $0,9965 \mathrm{bc}$ & $0,9958 \mathrm{~cd}$ & $0,9986 \mathrm{a}$ & $0,9951 \mathrm{~d}$ & 0,9964 & 0,11 \\
\hline Álcool (\% v/v) & $9,34 \mathrm{~d}$ & $10,55 \mathrm{ab}$ & $10,20 \mathrm{c}$ & $10,50 \mathrm{~b}$ & $10,10 \mathrm{c}$ & $10,81 \mathrm{a}$ & 10,25 & 2,75 \\
\hline Acidez total $\left(\mathrm{mq} \mathrm{L}^{-1}\right)$ & $83,5 \mathrm{~b}$ & $83,5 \mathrm{~b}$ & $90,0 \mathrm{a}$ & $83,1 \mathrm{~b}$ & $83,6 \mathrm{~b}$ & $83,5 \mathrm{~b}$ & 84,5 & 5,08 \\
\hline Acidez volátil (meq L ${ }^{-1}$ ) & $9,9 \mathrm{a}$ & $9,4 \mathrm{a}$ & $9,4 \mathrm{a}$ & $9,5 \mathrm{a}$ & $10,4 \mathrm{a}$ & $9,9 \mathrm{a}$ & 9,8 & 9,56 \\
\hline $\mathrm{pH}$ & $3,34 \mathrm{ab}$ & $3,34 \mathrm{ab}$ & $3,32 \mathrm{~b}$ & $3,37 \mathrm{a}$ & $3,32 \mathrm{~b}$ & $3,34 \mathrm{ab}$ & 3,34 & 1,00 \\
\hline Extrato seco $\left(\mathrm{g} \mathrm{L}^{-1}\right)$ & $22,6 \mathrm{~b}$ & $23,1 \mathrm{~b}$ & $23,7 \mathrm{~b}$ & $23,3 \mathrm{~b}$ & $30,9 \mathrm{a}$ & $22,2 \mathrm{~b}$ & 24,3 & 8,33 \\
\hline Extrato seco reduzido $\left(\mathrm{g} \mathrm{L}^{-1}\right)$ & $20,5 \mathrm{bc}$ & $21,1 \mathrm{bc}$ & $21,4 \mathrm{~b}$ & $21,0 \mathrm{bc}$ & 26,6 a & $19,9 \mathrm{c}$ & 21,7 & 5,60 \\
\hline Açúcares redutores $\left(\mathrm{g} \mathrm{L}^{-1}\right)$ & $3,1 \mathrm{~b}$ & $3,0 \mathrm{~b}$ & $3,3 \mathrm{~b}$ & $3,3 \mathrm{~b}$ & $5,3 \mathrm{a}$ & $3,3 \mathrm{~b}$ & 3,6 & 26,71 \\
\hline Relação álcool em peso/Extrato seco reduzido & $3,65 \mathrm{~d}$ & $4,02 \mathrm{~b}$ & $3,80 \mathrm{~cd}$ & $4,00 \mathrm{bc}$ & $3,06 \mathrm{e}$ & $4,36 \mathrm{a}$ & 3,82 & 4,99 \\
\hline Cinzas $\left(\mathrm{g} \mathrm{L}^{-1}\right)$ & $2,16 a b c$ & $2,06 \mathrm{c}$ & $2,18 \mathrm{ab}$ & $2,22 \mathrm{a}$ & $2,10 a b c$ & $2,08 \mathrm{bc}$ & 2,14 & 5,51 \\
\hline Alcalinidade das cinzas $\left(\mathrm{meq} \mathrm{L}^{-1}\right)$ & $19,0 \mathrm{~b}$ & $18,9 \mathrm{~b}$ & $19,4 \mathrm{~b}$ & $20,8 \mathrm{a}$ & $19,6 \mathrm{~b}$ & $18,9 \mathrm{~b}$ & 19,4 & 4,63 \\
\hline Polifenóis totais (I 280) & $16,4 \mathrm{~b}$ & $16,3 \mathrm{~b}$ & $20,0 \mathrm{a}$ & $19,1 \mathrm{a}$ & $16,7 \mathrm{~b}$ & $15,7 \mathrm{~b}$ & 17,4 & 10,81 \\
\hline Taninos $\left(\mathrm{g} \mathrm{L}^{-1}\right)$ & $0,4 \mathrm{a}$ & $0,4 \mathrm{a}$ & $0,5 \mathrm{a}$ & $0,5 \mathrm{a}$ & $0,4 \mathrm{a}$ & $0,4 \mathrm{a}$ & 0,41 & 30,08 \\
\hline Antocianinas $\left(\mathrm{mg} \mathrm{L}^{-1}\right)$ & $75,7 \mathrm{ab}$ & 85,7 a & 85,4 a & 82,6 ab & $65,8 \mathrm{~b}$ & $65,6 \mathrm{~b}$ & 76,8 & 22,08 \\
\hline $\mathrm{DO}(420 \mathrm{~nm})$ & $0,092 \mathrm{~b}$ & $0,086 \mathrm{~b}$ & $0,112 \mathrm{a}$ & $0,107 \mathrm{a}$ & $0,094 \mathrm{~b}$ & $0,090 \mathrm{~b}$ & 0,097 & 11,26 \\
\hline DO $(520 \mathrm{~nm})$ & $0,090 \mathrm{bc}$ & $0,084 \mathrm{c}$ & $0,122 \mathrm{a}$ & $0,100 \mathrm{bc}$ & $0,109 \mathrm{ab}$ & $0,092 \mathrm{bc}$ & 0,100 & 20,60 \\
\hline Intensidade de cor (DO 420 + DO 520) & $0,183 \mathrm{bc}$ & $0,170 \mathrm{c}$ & $0,234 \mathrm{a}$ & $0,207 a b$ & $0,203 \mathrm{ab}$ & $0,182 \mathrm{bc}$ & 0,196 & 15,63 \\
\hline Coloração (DO 420/DO 520) & $1,028 \mathrm{ab}$ & $1,031 \mathrm{ab}$ & $0,935 \mathrm{~b}$ & $1,089 \mathrm{a}$ & $0,953 \mathrm{~b}$ & $0,984 \mathrm{ab}$ & 1,003 & 10,20 \\
\hline Dióxido de enxofre livre $\left(\mathrm{mg} \mathrm{L}^{-1}\right)$ & $18,9 \mathrm{ab}$ & $21,7 \mathrm{a}$ & $18,7 \mathrm{ab}$ & $20,2 \mathrm{ab}$ & $11,4 \mathrm{c}$ & $15,4 \mathrm{bc}$ & 17,7 & 28,00 \\
\hline
\end{tabular}

* Médias seguidas por letras distintas, na linha, diferem entre si pelo teste de Tukey a 1\% de probabilidade de erro.

Ciência Rural, v.35, n.2, mar-abr, 2005. 
acidez elevado desse vinho na Serra Gaúcha (RIZZON et al., 2000; RIZZON \& MIELE, 2001, 2002).

Os produtos utilizados para correção do mosto não interferiram no teor de acidez volátil do vinho Isabel. Quanto ao extrato seco reduzido, o aumento observado não foi proporcional ao álcool formado, uma vez que se detectou um aumento dos valores da relação álcool em peso/extrato seco reduzido. Os maiores desequilíbrios nos valores dessa relação foram observados nos vinhos corrigidos com álcool vínico, que aumentou acima da média o etanol, e naqueles corrigidos com glicose de milho, que aumentou consideravelmente o extrato seco. A relação álcool em peso/extrato seco reduzido é utilizada para detectar correções excessivas. Essa relação, quando muito elevada, é um indicativo de vinagem e aguagem dos vinhos. A legislação brasileira estabelece os valores máximos dessa relação de, respectivamente, 4,8 e 5,2 para os vinhos tintos de mesa e fino. Para os vinhos rosados, o valor máximo da relação é 6,0, enquanto que para os vinhos brancos é 6,5 (BRASIL, 1974).

Os teores dos açúcares redutores foi mais elevado no vinho corrigido com glicose de milho, devido a sua própria constituição, enquanto que o dióxido de enxofre livre foi mais baixo nesses vinhos e naqueles corrigidos com álcool vínico, o que indica formação de maior quantidade de componentes que o combinam.

Os produtos utilizados na correção do mosto interferiram de modo significativo nas cinzas dos vinhos, observou-se valor mais baixo no vinho corrigido com sacarose, devido ao teor baixo de cinzas neste produto.
Os vinhos corrigidos com mosto concentrado e açúcar mascavo apresentaram teores mais elevados de polifenóis totais. No caso do mosto concentrado, além do açúcar, estão presentes constituintes responsáveis pela cor, como as antocianinas e os taninos. No entanto, não se observou variação significativa na concentração do vinho Isabel em relação aos produtos utilizados na correção.

Com relação aos índices de cor (DO 420 e DO 520), o mosto concentrado e o açúcar mascavo favoreceram o aumento da cor vermelha (DO 520) do vinho Isabel. No caso do mosto concentrado, observou-se maior impacto na cor vermelha, enquanto que o açúcar mascavo interferiu mais na cor amarela (DO 420). A interferência do açúcar mascavo é extremamente negativa para a qualidade do vinho, pois atribui-lhe aspecto de vinho oxidado. Por isso, não deve ser recomendado para a chaptalização dos mostos.

A variação do teor de elementos minerais do vinho em função do produto utilizado na correção do mosto está indicada na tabela 2. Constata-se que o açúcar mascavo e o mosto concentrado contribuíram para aumentar o teor de potássio no vinho. No caso desses dois produtos, o potássio é um constituinte natural importante liberado para o mosto.

O sódio aparece em concentração mais alta nos vinhos corrigidos especialmente com glicose de milho, e também com açúcar mascavo, o que mostra que esses dois produtos incorporam esse mineral ao vinho. O sódio é um cátion muito influenciado pelos produtos enológicos, visto que seu teor é naturalmente baixo nos vinhos (RIZZON \& SALVADOR, 1987). A

Tabela 2 - Influência de produtos utilizados na correção do mosto no teor de minerais do vinho Isabel.

\begin{tabular}{|c|c|c|c|c|c|c|c|c|}
\hline \multicolumn{9}{|c|}{ Produtos utilizados* } \\
\hline Minerais $\left(\mathrm{mg} \mathrm{L}^{-1}\right)$ & Testemunha & Sacarose & $\begin{array}{c}\text { Mosto } \\
\text { concentrado }\end{array}$ & $\begin{array}{l}\text { Açúcar } \\
\text { mascavo }\end{array}$ & $\begin{array}{l}\text { Glicose de } \\
\text { milho }\end{array}$ & $\begin{array}{l}\text { Álcool } \\
\text { vínico }\end{array}$ & Média geral & $\mathrm{CV}(\%)$ \\
\hline Potássio & $815 \mathrm{~b}$ & $791 \mathrm{bc}$ & $824 \mathrm{ab}$ & $856 \mathrm{a}$ & $769 \mathrm{c}$ & $812 b$ & 811 & 4,83 \\
\hline Sódio & $2,1 \mathrm{c}$ & $2,3 \mathrm{c}$ & $4,1 \mathrm{c}$ & $12,6 b$ & $33,0 \mathrm{a}$ & $3,1 \mathrm{c}$ & 9,5 & 54,54 \\
\hline Cálcio & $75,9 \mathrm{ab}$ & $71,3 \mathrm{abc}$ & $68,4 \mathrm{c}$ & $69,8 \mathrm{bc}$ & $76,3 \mathrm{a}$ & $74,0 \mathrm{abc}$ & 72,6 & 8,32 \\
\hline Magnésio & $109,9 \mathrm{~b}$ & $108,9 \mathrm{~b}$ & $119,1 \mathrm{a}$ & $113,0 \mathrm{~b}$ & $108,8 \mathrm{~b}$ & $108,1 \mathrm{~b}$ & 111,3 & 4,43 \\
\hline Manganês & $2,1 \mathrm{ab}$ & $2,0 \mathrm{bc}$ & $2,2 \mathrm{a}$ & $2,2 \mathrm{a}$ & $1,8 \mathrm{c}$ & $2,0 \mathrm{bc}$ & 2,0 & 9,16 \\
\hline Ferro & $1,7 \mathrm{bc}$ & $1,7 \mathrm{bc}$ & $1,8 \mathrm{~b}$ & $2,4 \mathrm{a}$ & $1,7 \mathrm{bc}$ & $1,5 \mathrm{c}$ & 1,8 & 14,42 \\
\hline Cobre & $0,7 \mathrm{ab}$ & $1,0 \mathrm{a}$ & $0,6 a b$ & $0,8 \mathrm{ab}$ & $0,5 \mathrm{~b}$ & $0,8 \mathrm{ab}$ & 0,7 & 59,27 \\
\hline Zinco & $1,8 \mathrm{a}$ & $1,7 \mathrm{a}$ & $1,5 a b$ & $1,8 \mathrm{a}$ & $1,4 \mathrm{~b}$ & $1,8 \mathrm{a}$ & 1,7 & 19,60 \\
\hline Lítio** & $2,1 \mathrm{bc}$ & $2,0 \mathrm{c}$ & $2,4 \mathrm{a}$ & $2,3 a b$ & $2,2 \mathrm{abc}$ & $1,6 \mathrm{~d}$ & 2,1 & 11,44 \\
\hline Fósforo & $112,1 \mathrm{ab}$ & $109,1 \mathrm{abc}$ & $113,8 \mathrm{a}$ & $112,0 \mathrm{ab}$ & $103,7 \mathrm{c}$ & $106,0 \mathrm{bc}$ & 109,4 & 6,84 \\
\hline
\end{tabular}

* Médias seguidas por letras distintas, na linha, diferem entre si pelo teste de Tukey a 1\% de probabilidade de erro.

$* * \mu \mathrm{g} \mathrm{L}{ }^{-1}$ 
incorporação de sódio pela glicose de milho e pelo açúcar mascavo interferem negativamente na qualidade do vinho, pois são produtos estranhos ao mesmo.

Observou-se uma tendência de redução do teor de cálcio em função do produto utilizado na chaptalização, principalmente para o mosto concentrado e açúcar mascavo. De modo geral, o aumento do teor de etanol favorece a precipitação do tartarato de cálcio. Como os sais de magnésio são mais solúveis que os de cálcio, seu teor foi mais elevado, especialmente no vinho corrigido com mosto concentrado, além de ser incorporado pelo produto adicionado.

Em relação ao ferro, constatou-se teor mais elevado no vinho corrigido com açúcar mascavo o que indica incorporação desse cátion através desse produto. Os teores de cobre encontrados foram significativamente diferentes entre a sacarose e a glicose de milho. Os teores desses minerais são considerados elevados e podem representar problemas para a estabilização dos mesmos.

O teor de fósforo foi menor no vinho corrigido com glicose de milho, mas não diferiu significativamente da sacarose e do álcool vínico, provavelmente devido à reduzida presença deste elemento nesses produtos.

\section{CONCLUSÕES}

Não são recomendados para a chaptalização do vinho Isabel da Serra Gaúcha o mosto concentrado, o açúcar mascavo e a glicose de milho, pois interferem na composição química e apresentam baixo rendimento alcoólico.

A sacarose é o açúcar recomendado para efetuar a chaptalização do vinho Isabel da Serra Gaúcha, no entanto, o álcool vínico nas menores necessidades de correção também pode ser utilizado.

\section{REFERÊNCIAS BIBLIOGRÁFICAS}

AMATI, A. et al. Prove di arricchimento con mosto concentrado depurato. Vini d'Italia, Brescia, v.125, p.59-63, 1980.
BRASIL. Ministério da Agricultura. Secretaria Nacional de Defesa Agropecuária. Secretaria de Inspeção Vegetal, Brasília, DF. Complementação de padrões de identidade e qualidade para cerveja, vinho, vinho de frutas, fermentado de cana, saquê, filtrado doce, hidromel, jeropiga, mistela, sidra, vinagre. Brasília: Imprensa Nacional, 1974. 109p.

BRASIL. Secretaria de Defesa Agropecuária, Brasília, DF. Submete à consulta pública a metodologia da análise isotópica ${ }^{13} \mathrm{C}$ e ${ }^{12} \mathrm{C}$ em produtos e subprodutos de plantas do ciclo fotossintético $\mathbf{C}_{\mathbf{3}}$ e $\mathbf{C}_{\mathbf{4}}$. Brasília : Diário Oficial, n. 178, 2000. 3p.

CHAPTAL, J.A. L'art de faire le vin. Marseille : Jeanne Laffitte, 1981. 381p. (Réimpression de l'édition de Paris, 1819).

GIANNESSI, P.; MATTA, M. Trattato di scienza e tecnica enologica. Analisi e controllo dei mosti e dei vini. Brescia : AEB, 1987. 349p.

PERKIN-ELMER. Analytical methods for atomic absorption spectrophotometry. Norwalk: Perkin-Elmer, 1976. 432 p.

RIBÉREAU-GAYON, P. et al. Traité d'oenologie. 2. Chimie du vin, stabilization e traitements. Paris : Dunod, 1998. 519p.

RIBÉREAU-GAYON, P.; STONESTREET, E. Dosage des tanins du vin rouge et détermination de leur structure. Chimie Analytique, Paris, v.48, n.4, p.188-196, 1966.

RIBÉREAU-GAYON, P.; STONESTREET, E. Le dosage des anthocyanes dans les vins rouges. Bulletin de la Societé Chimique de France, Paris, v.9, n.419, p.2649-2652, 1965.

RIZZON, L.A.; MIELE, A. Concentração de ácido tartárico nos vinhos da Serra Gaúcha. Ciência Rural, Santa Maria, v.31, n.5, p. $893-895,2001$

RIZZON, L.A.; MIELE, A. Acidez na vinificação em tinto das uvas Isabel, Cabernet Sauvignon e Cabernet Franc. Ciência Rural, Santa Maria, v.32, n.3, p.511-515, 2002.

RIZZON, L.A. et al. Avaliação da uva cv. Isabel para a elaboração de vinho tinto. Ciência e Tecnologia de Alimentos, Campinas, v.20, n.1, p.115-121, 2000.

RIZZON, L.A.; SALVADOR, M.B.G. Teores de cátions dos vinhos da Microrregião Homogênea Vinicultora de Caxias do Sul (MRH 311). Bento Gonçalves : EMBRAPA-CNPUV, 1987. 4p. (EMBRAPA CNPUV, Comunicado Técnico, 4).

ROSEK, F. Causas determinantes da chaptalização dos mostos no Brasil. Bento Gonçalves, 1965. 27 p. Mimeografado.

TEDESCO, M. et al. Análise de solo, plantas e outros metais. Porto Alegre : Departamento de Solos, Faculdade de Agronomia, UFRGS, 1995. 174 p. (Boletim Técnico, 5). 